\title{
Study of the stability of dried tomato halves during shelf-life to minimise oxidative damage
}

\author{
B Zanoni, ${ }^{1 *}$ E Pagliarini ${ }^{2}$ and R Foschino ${ }^{3}$ \\ ${ }^{1}$ DIVAPRA, Settore Microbiologia e Industrie Agrarie, Università di Torino, Via Leonardo da Vinci 44, I-10095 Grugliasco, Torino, Italy \\ ${ }^{2}$ diSTAM, Sezione Tecnologie Alimentari, Università di Milano, Via Celoria 2, I-20133 Milano, Italy \\ ${ }^{3}$ diSTAM, Sezione Microbiologia Agraria, Alimentare, Ecologica, Università di Milano, Via Celoria 2, I-20133 Milano, Italy
}

\begin{abstract}
Optimal operating conditions for storage of dried tomato halves were investigated to obtain decreased oxidative damage, evaluated in terms of colour variation, combined with microbial stability of the product, ie inhibition of growth of eumycetes. Experiments were planned using a saturated factorial design. Variables studied were the moisture content of dried tomato halves in the range 10$60 \%$, temperature in the range $5-30^{\circ} \mathrm{C}$ and storage time in the range 1-38 days. Eighteen storage experiments were carried out in the dark under vacuum at the storage conditions indicated by the experimental design. At the end of each experiment, surface colour was measured by a tristimulus colorimeter, and growth of eumycetes was evidenced by olfactory and visual perception, followed by qualitative microbial analysis. Eumycetes were present in all stored products, except that at $10 \%$ moisture, and, generally speaking, storage conditions did not allow micro-organisms to grow. From isoresponse curves the optimal region for storage to minimise oxidative damage was extrapolated, which was represented by residual moisture values between 20 and $40 \%$ and $\leq 18^{\circ} \mathrm{C}$ storage temperature, with a minimum point of colour variation at approximately $30 \%$ moisture content and $10^{\circ} \mathrm{C}$. (C) 2000 Society of Chemical Industry
\end{abstract}

Keywords: tomato; oxidative damage; shelf-life; drying

\section{INTRODUCTION}

Drying of tomato halves causes oxidative heat damage to the product, shown by both a loss of ascorbic acid and an increase in 5-hydroxymethyl-2-furfural (HMF) content. ${ }^{1}$ As a result, undesirable colour and appearance changes occur in dried tomatoes. Conversely, no significant changes in lycopene content occur during drying. ${ }^{1}$ This is probably due to both the heat resistance of lycopene ${ }^{2-5}$ and the antioxidant activity of Maillard reaction derivatives. ${ }^{6,7}$

Optimisation of tomato drying in terms of both maximising the drying rate and minimising oxidative heat damage requires low temperatures for short times (LTST). LTST treatments may be applied by drying tomatoes in small pieces, eg slices, quarters or cubes. A reduction in thickness corresponds to an increase in moisture diffusion, resulting in fast water removal. LTST treatments may also be applied by drying tomato halves, resulting in partial water removal; in this way, intermediate-moisture tomato products can be obtained. In recent years the commercial importance of dried tomato halves has been increasing, since they can be used as a component for several foods such as pizza.

Several studies ${ }^{1,5,8}$ have shown that oxidative damage to dried tomatoes also occurs during storage. In this case, browning has been associated with a marked lycopene loss of dried tomatoes. There are few data on optimal operating conditions of storage.

The aim of this work was (i) to study the stability of tomato halves during storage as a function of moisture content and time-temperature conditions and (ii) to find the optimal range of storage operating conditions, particularly to minimise oxidative damage.

\section{EXPERIMENTAL}

\section{Optimisation procedure}

This study was carried out using multivariate statistical analysis..$^{9}$ A saturated factorial design by the central composite design method was first used to evaluate the effect of simultaneous variations in variables. Experiments were then carried out. Finally, a response surface model (RSM) was determined to find both the optimal conditions for the phenomenon studied and the level of individual variables required to reach a particular response level.

\section{Factorial design}

Variables studied were the moisture content of dried tomato halves and storage time and temperature.

Moisture content was related to water activity by the following Halsey model, which has already been used

\footnotetext{
* Correspondence to: B Zanoni, DIVAPRA, Settore Microbiologia e Industrie Agrarie, Università di Torino, Via Leonardo da Vinci 44, I-10095 Grugliasco, Torino, Italy

E-mail: zanoni@agraria.unito.it

(Received 10 February 2000; revised version received 28 July 2000; accepted 21 August 2000)
} 
Table 1. Limiting values for variables used in the factorial design

\begin{tabular}{lcc}
\hline Variable & $\begin{array}{c}\text { Minimum value } \\
(-)\end{array}$ & $\begin{array}{c}\text { Maximum value } \\
(+)\end{array}$ \\
\hline Moisture content $(\%)$ & 20 & 50 \\
Temperature $\left({ }^{\circ} \mathrm{C}\right)$ & 10 & 25 \\
Time (days) & 8 & 30 \\
\hline
\end{tabular}

in other studies on tomatoes: ${ }^{10}$

$$
a_{\mathrm{w}}=\exp \left(-\frac{B}{n_{\mathrm{s}}^{A}}\right)
$$

where $n_{\mathrm{s}}$ is in $\mathrm{gg}^{-1}$ dry matter, $A=0.93$ and $B=0.103$. Values for model parameters were determined in a previous study ${ }^{1}$ by fitting experimental data of the desorption isotherm of tomato halves.

Since the aim of this work was to find the optimal storage conditions to minimise oxidative damage, variables such as light intensity and oxygen content were not considered owing to the their known, relevant effects on oxidative damage to dried tomatoes during storage. ${ }^{1,5,8}$ Experiments were carried out in the dark under vacuum storage conditions.

To apply the saturated factorial design, experimental data were collected using two levels for each of the variables studied. Thus information was obtained which was necessary to determine how the response was influenced by single factors and by their interactions. Table 1 shows the limiting values for the variables used.

The number of experiments necessary for a saturated factorial design by the central composite design method was $2^{n}+2 n+4$, where $n$ is the number of variables. ${ }^{9}$ The RSM model requires:

- experiments carried out at the point where all the variables take on their average values (centre point) - the centre point is replicated several times to provide an independent estimate of the experimental error;

- experiments carried out at a distance of 1.68 from the centre point (by adding a pair of experiments along the co-ordinate axes at a distance equal to half the diagonal of the cube);

- experiments carried out at the edges of a cube with the centre point in the middle and with its sides corresponding to each variable range $(-1$ to +1$)$.

Table 2 shows the variable values used for the 18 shelf-life experiments.

\section{Shelf-life experiments}

Drying

Ripe, fresh tomatoes of Cencara cultivar (Peviani srl, Milan, Italy) were selected in order to have homogeneous samples in terms of drying time and surface colour. $^{1}$

Six drying tests were carried out to obtain samples for the 18 shelf-life experiments.
Thirty tomatoes $5.5 \mathrm{~cm}$ in diameter were selected for each drying test. Tomatoes were cut into halves with a knife, and parenchyma and seeds were removed. For each drying test, 40 tomato halves were used, and 20 tomato halves were used to characterise fresh tomatoes in terms of moisture content and surface colour.

Tomato halves were dried in a pilot-plant cabinet air dryer, designed and built by Thermo Lab (Milan, Italy), following the procedure of Zanoni et al. ${ }^{1}$ The 40 halves were placed on a perforated stainless steel tray $(40 \mathrm{~cm} \times 60 \mathrm{~cm})$ in eight rows of five halves. The tray was connected to a balance to measure the tomato weight during drying. Drying was carried out at $80^{\circ} \mathrm{C}$ and an air flow rate of $1.5 \mathrm{~m} \mathrm{~s}^{-1}$ by through-flow. Tomatoes were dried to the different final moisture contents reported in Table 2 .

At the end of drying, tomato halves were immediately packed under vacuum in several airtight, watervapour-proof, plastic bags. Bags were immediately chilled at $3^{\circ} \mathrm{C}$ for $15 \mathrm{~min}$ and then transferred to experimental storage conditions.

For each drying test, 10 dried tomato halves were used to characterise dried tomatoes in terms of surface colour and growth of eumycetes.

\section{Storage}

Dried halves were stored in the dark under the timetemperature conditions reported in Table 2, using five thermostatic cells. Samples taken from the cells were characterised in terms of moisture content, surface colour and growth of eumycetes.

\section{Analyses}

Moisture content (\%) was determined by gravimetry in triplicate following the method described by Zanoni et al. ${ }^{1}$

Table 2. Operating conditions of shelf-life experiments planned by the factorial design

\begin{tabular}{|c|c|c|c|}
\hline Experiment & $\begin{array}{c}\text { Moisture } \\
\text { content (\%) }\end{array}$ & Temperature $\left({ }^{\circ} \mathrm{C}\right)$ & Time (days) \\
\hline 1 & 10 & 17.5 & 19.0 \\
\hline 2 & 60 & 17.5 & 19.0 \\
\hline 3 & 35 & 5.0 & 19.0 \\
\hline 4 & 35 & 30.0 & 19.0 \\
\hline 5 & 35 & 17.5 & 0.5 \\
\hline 6 & 35 & 17.5 & 37.5 \\
\hline 7 & 20 & 10.0 & 8.0 \\
\hline 8 & 50 & 10.0 & 8.0 \\
\hline 9 & 20 & 25.0 & 8.0 \\
\hline 10 & 50 & 25.0 & 8.0 \\
\hline 11 & 20 & 10.0 & 30.0 \\
\hline 12 & 50 & 10.0 & 30.0 \\
\hline 13 & 20 & 25.0 & 30.0 \\
\hline 14 & 50 & 25.0 & 30.0 \\
\hline 15 & 35 & 17.5 & 19.0 \\
\hline 16 & 35 & 17.5 & 19.0 \\
\hline 17 & 35 & 17.5 & 19.0 \\
\hline 18 & 35 & 17.5 & 19.0 \\
\hline
\end{tabular}


Surface colour of both fresh and dried tomatoes was measured by the Hunter colorimetric system using a Chroma Meter CR-210 tristimulus colorimeter (Minolta Co, Tokyo, Japan). $L^{*}, a^{*}$ and $b^{*}$ parameters of samples were measured, and $\Delta E$ values were calculated for dried samples as follows: ${ }^{11}$

$$
\Delta E=\sqrt{\left(L_{t}^{*}-L_{0}^{*}\right)^{2}+\left(a_{t}^{*}-a_{0}^{*}\right)^{2}+\left(b_{t}^{*}-b_{0}^{*}\right)^{2}}
$$

where $L_{0}^{*}, a_{0}^{*}$ and $b_{0}^{*}$ are the colour parameters of dried tomato halves at time zero of storage and $L_{t}^{*}, a_{t}^{*}$ and $b_{t}^{*}$ are the colour parameters at time $t$ of storage. The colour variation was used as a fast, simple index of oxidative damage. ${ }^{12,13}$ Seven measurements of colour parameters were carried out for each sample.

Growth of eumycetes on dried tomato halves was evidenced in duplicate by a two-step method involving olfactory (ie presence of off-flavours for yeasts) and visual (ie presence of mycelia for moulds) perception of the samples, followed by qualitative microbial analysis on a selective substrate. ${ }^{14}$ Microbial analyses were carried out by incubation under agitation of samples in enriched malt broth at $25^{\circ} \mathrm{C}$ for $48 \mathrm{~h}$. An aliquot of broth was then spread by a swab on a slide (Food Slide type 1, Pbi International, Milan, Italy) of Rose Bengal CAF agar. The slide was inserted into its tube, which was incubated at $30^{\circ} \mathrm{C}$ for $48 \mathrm{~h}$. Growth of moulds and yeasts was evidenced by visual perception of mycelia and colonies respectively.

This two-step method was able to show the following possible situations:

- positive sensory perception combined with a positive result from the microbial analysis showed that the storage conditions were able to grow eumycetes;

- negative sensory perception combined with a positive result from the microbial analysis showed that eumycetes were present on dried tomato halves, but the storage conditions were not able to grow them;

- negative sensory perception combined with a negative result from the microbial analysis showed that eumycetes were not present on dried tomato halves since they had been inactivated during drying.

\section{Response surface model}

The following polynomial equation, describing the RSM of $\Delta E$ as a function of the variables studied, was set up:

$$
\begin{aligned}
\Delta E= & \beta_{0}+\beta_{1} M+\beta_{2} T+\beta_{3} t+\beta_{4} M T \\
& +\beta_{5} M t+\beta_{6} T t+\beta_{7} M^{2}+\beta_{8} T^{2}+\beta_{9} t^{2}
\end{aligned}
$$

where $M$ is the moisture content (\%) of dried tomato halves, $T$ is the storage temperature and $t$ is the storage time.

Variables present in the linear terms represent the co-ordinates of the maximum value predicted; variables present in the quadratic terms represent the surface curvature; and the bifactorial cross-products represent the directions of axes of the geometric figure obtained by sectioning the surface area.

Effects of individual variables and their interactions were calculated by applying the Yates algorithm. ${ }^{9}$

\section{Data processing}

The multivariate statistical analysis to apply the saturated factorial design and to determine the RSM was carried out using the Unscrambler ${ }^{\circledR}$ version 7.01 (Camo AS, Trondheim, Norway) software package.

\section{RESULTS AND DISCUSSION Drying and storage tests}

Fig 1 shows the kinetics of the different drying tests
Figure 1. Moisture content (\% on wet basis) of tomato halves versus drying time at $80^{\circ} \mathrm{C}$. Symbols refer to the final moisture contents: $\bullet, 10 \% ; \mathbf{\square}, 20 \%$; A, $35 \% ; \bigcirc, 50 \% ; *, 60 \%$.

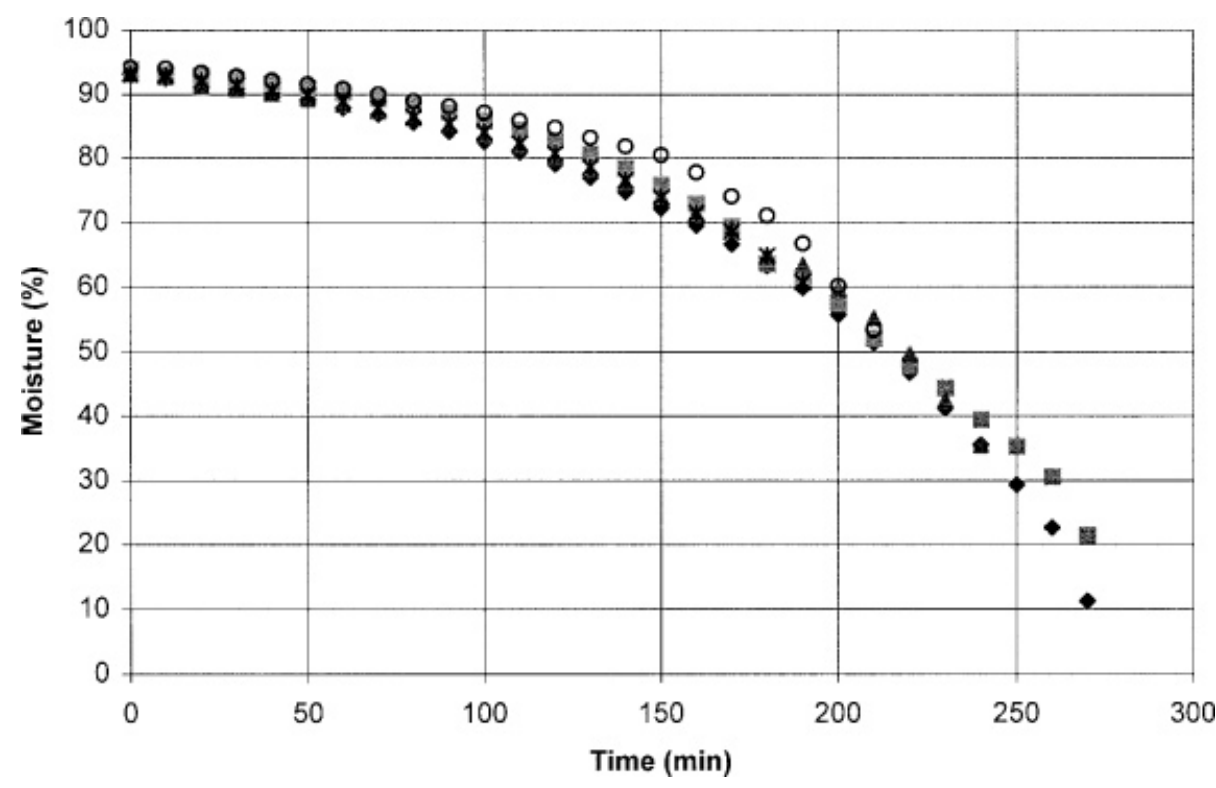



different moisture contents

\begin{tabular}{|c|c|c|c|}
\hline Sample & Time & $\Delta \mathrm{E}$ & Eumycetes \\
\hline $\begin{array}{l}10 \% \text { moisture } \\
\left(a_{w}=0.45\right)\end{array}$ & $\begin{array}{l}t=0 \\
t=19 \text { days at } 17.5^{\circ} \mathrm{C}\end{array}$ & $4.18 \pm 0.56$ & $\begin{array}{l}-1- \\
-1-\end{array}$ \\
\hline $\begin{array}{l}20 \% \text { moisture } \\
\left(a_{w}=0.69\right)\end{array}$ & $\begin{array}{l}t=0 \\
t=8 \text { days at } 10^{\circ} \mathrm{C} \\
t=30 \text { days at } 10^{\circ} \mathrm{C} \\
t=8 \text { days at } 25^{\circ} \mathrm{C} \\
t=30 \text { days at } 25^{\circ} \mathrm{C}\end{array}$ & $\begin{aligned}- & \\
5.55 & \pm 0.77 \\
6.14 & \pm 0.63 \\
11.36 & \pm 1.27 \\
12.81 & \pm 1.52\end{aligned}$ & $\begin{array}{l}-1+ \\
-1+ \\
-1+ \\
-1+ \\
-1+\end{array}$ \\
\hline $\begin{array}{l}35 \% \text { moisture } \\
\left(a_{w}=0.83\right)\end{array}$ & $\begin{array}{l}t=0 \\
t=0.5 \text { day at } 17.5^{\circ} \mathrm{C} \\
t=19 \text { days at } 17.5^{\circ} \mathrm{C} \\
t=19 \text { days at } 17.5^{\circ} \mathrm{C} \\
t=37.5 \text { days at } 17.5^{\circ} \mathrm{C}\end{array}$ & $\begin{array}{r}- \\
3.34 \pm 1.90 \\
4.04 \pm 0.33 \\
4.41 \pm 0.23 \\
10.06 \pm 1.40\end{array}$ & $\begin{array}{l}-1+ \\
-1+ \\
-1+ \\
-1+ \\
-1+\end{array}$ \\
\hline $\begin{array}{l}35 \% \text { moisture } \\
\left(a_{w}=0.83\right)\end{array}$ & $\begin{array}{l}t=0 \\
t=19 \text { days at } 5^{\circ} \mathrm{C} \\
t=19 \text { days at } 17.5^{\circ} \mathrm{C} \\
t=19 \text { days at } 17.5^{\circ} \mathrm{C} \\
t=19 \text { days at } 30^{\circ} \mathrm{C}\end{array}$ & $\begin{aligned} &- \\
& 1.78 \pm 0.18 \\
& 3.75 \pm 0.46 \\
& 3.89 \pm 0.33 \\
& 12.72 \pm 1.57\end{aligned}$ & $\begin{array}{l}-1+ \\
-1+ \\
-1+ \\
-1+ \\
-1+\end{array}$ \\
\hline $\begin{array}{l}50 \% \text { moisture } \\
\left(a_{w}=0.90\right)\end{array}$ & $\begin{array}{l}t=0 \\
t=8 \text { days at } 10^{\circ} \mathrm{C} \\
t=30 \text { days at } 10^{\circ} \mathrm{C} \\
t=8 \text { days at } 25^{\circ} \mathrm{C} \\
t=30 \text { days at } 25^{\circ} \mathrm{C}\end{array}$ & $\begin{array}{r}- \\
9.30 \pm 0.53 \\
7.83 \pm 0.40 \\
7.55 \pm 0.39 \\
19.58 \pm 1.94\end{array}$ & $\begin{array}{l}-1+ \\
-1+ \\
-1+ \\
-1+ \\
+/+\end{array}$ \\
\hline $\begin{array}{l}60 \% \text { moisture } \\
\left(a_{w}=0.93\right)\end{array}$ & $\begin{array}{l}t=0 \\
t=19 \text { days at } 17.5^{\circ} \mathrm{C}\end{array}$ & $11.53 \pm 1.26$ & $\begin{array}{l}-1+ \\
-1+\end{array}$ \\
\hline
\end{tabular}

carried out to reach the final moisture contents of dried tomato halves (ie 10, 20, 35, 50 and $60 \%$ ) as defined by the saturated factorial design (Table 2).

Approximately $4 \mathrm{~h}$ and $30 \mathrm{~min}$ was required to remove water from tomato halves to $10 \%$ moisture and $3 \mathrm{~h}$ to remove water to $60 \%$ moisture. The different drying tests were carried out by a standard operating procedure, as evidenced by the similar kinetics.

Table 3 shows results from storage tests with different moisture contents of tomato halves. Moisture and water activity values for samples $\left(a_{\mathrm{w}}\right)$ determined by eqn (1) are also reported. It is evident that moisture contents include a wide range of water activity.

Results from microbial growth are marked with signs: the first sign refers to the olfactory and visual perception and the second sign to the microbial analysis. Apart from samples at 10 and 50\% moisture, eumycetes were present in all samples, and their growth was inhibited by the storage conditions (ie $-/+$ signs in Table 3). At $10 \%$ moisture, eumycetes were not present (ie $-/$-signs in Table 3 ), suggesting that yeasts and moulds were inactivated during drying. At $50 \%$ moisture, growth of eumycetes was found on the sample stored at $25^{\circ} \mathrm{C}$ for 30 days (ie $+/+$ signs in Table 3), indicating that microbial growth was favoured by the storage conditions.

\section{Optimisation by RSM}

Table 4 shows the effects of individual variables and their interactions with respect to the RSM of $\Delta E$ (see eqn (3).
It can be seen that storage temperature was the most important variable, whereas time and moisture content were less important. The minimum point for $\Delta E$ (ie 2.17) was predicted by the polynomial model as follows: storage of tomato halves with $27 \%$ moisture content at $10^{\circ} \mathrm{C}$ for 21 days. These conditions were tested experimentally by drying tomato halves to $30 \%$ final moisture, followed by storage at $10^{\circ} \mathrm{C}$ for 20 days. A measured value of $\Delta E=3.25 \pm 0.26$ was obtained versus a calculated value of $\Delta E=2.31$; the polynomial model was validated by the good reproducibility of the result.

The application of multiple regression analysis to $\Delta E$ data in Table 3 allowed us to determine response surfaces. Since these surfaces cannot be easily described, the relevant isoresponse curves are reported here (Figs 2-4).

Fig 2 shows the effect of temperature and time on

Table 4. Effects of individual variables and their interactions

\begin{tabular}{lc}
\hline Factor & Estimated effect \\
\hline Average $\left(\beta_{0}\right)$ & 3.901 \\
Moisture $\left(\beta_{1}\right)$ & 0.101 \\
Temperature $\left(\beta_{2}\right)$ & 0.339 \\
Time $\left(\beta_{3}\right)$ & 0.159 \\
Moisture $\times$ temperature $\left(\beta_{4}\right)$ & -0.248 \\
Moisture $\times$ time $\left(\beta_{5}\right)$ & 0.855 \\
Temperature $\times$ time $\left(\beta_{6}\right)$ & 1.443 \\
Moisture $\left(\beta_{7}\right)$ & 1.531 \\
Temperature $^{2}\left(\beta_{8}\right)$ & 1.360 \\
Time $^{2}\left(\beta_{9}\right)$ & 1.203 \\
\hline
\end{tabular}


Figure 2. Isoresponse curves for $\Delta E$ as a function of temperature and time at $35 \%$ moisture content.

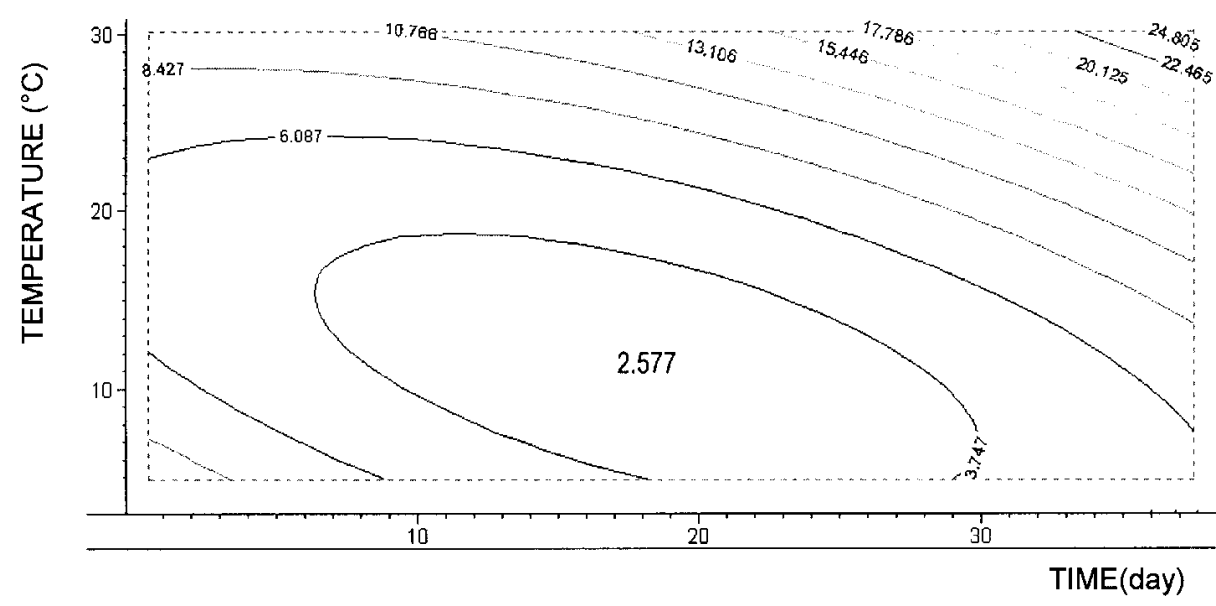

$\Delta E$ at the moisture content value of the centroid of the central composite design (ie 35\%). A very small variation in $\Delta E$ (ie 2.58-6.09) occurred in dried tomato halves up to approximately 40 days of storage if the storage temperature was low (ie $5-10^{\circ} \mathrm{C}$ ). At a storage temperature of $15-18^{\circ} \mathrm{C}$ the time required for minimum variation in $\Delta E$ decreased to approximately 30 days of storage.

Fig 3 shows the effect of moisture and time on $\Delta E$ at the storage temperature of the centroid of the central composite design (ie $17.5^{\circ} \mathrm{C}$ ). No considerable variation in $\Delta E$ (ie 3.28-6.09) occurred in dried tomato halves at $12-50 \%$ moisture content. The optimal range to minimise colour variation at the longest storage time (approximately 30 days) was 20-40\% moisture content. Colour variation was also promoted at $<12$ and $>50 \%$ moisture content.

Finally, Fig 4 shows the effect of moisture and temperature on $\Delta E$ at the storage time of the centroid of the central composite design (ie 19 days). No
Figure 3. Isoresponse curves for $\Delta E$ as a function of moisture content and time at $17.5^{\circ} \mathrm{C}$ storage temperature.
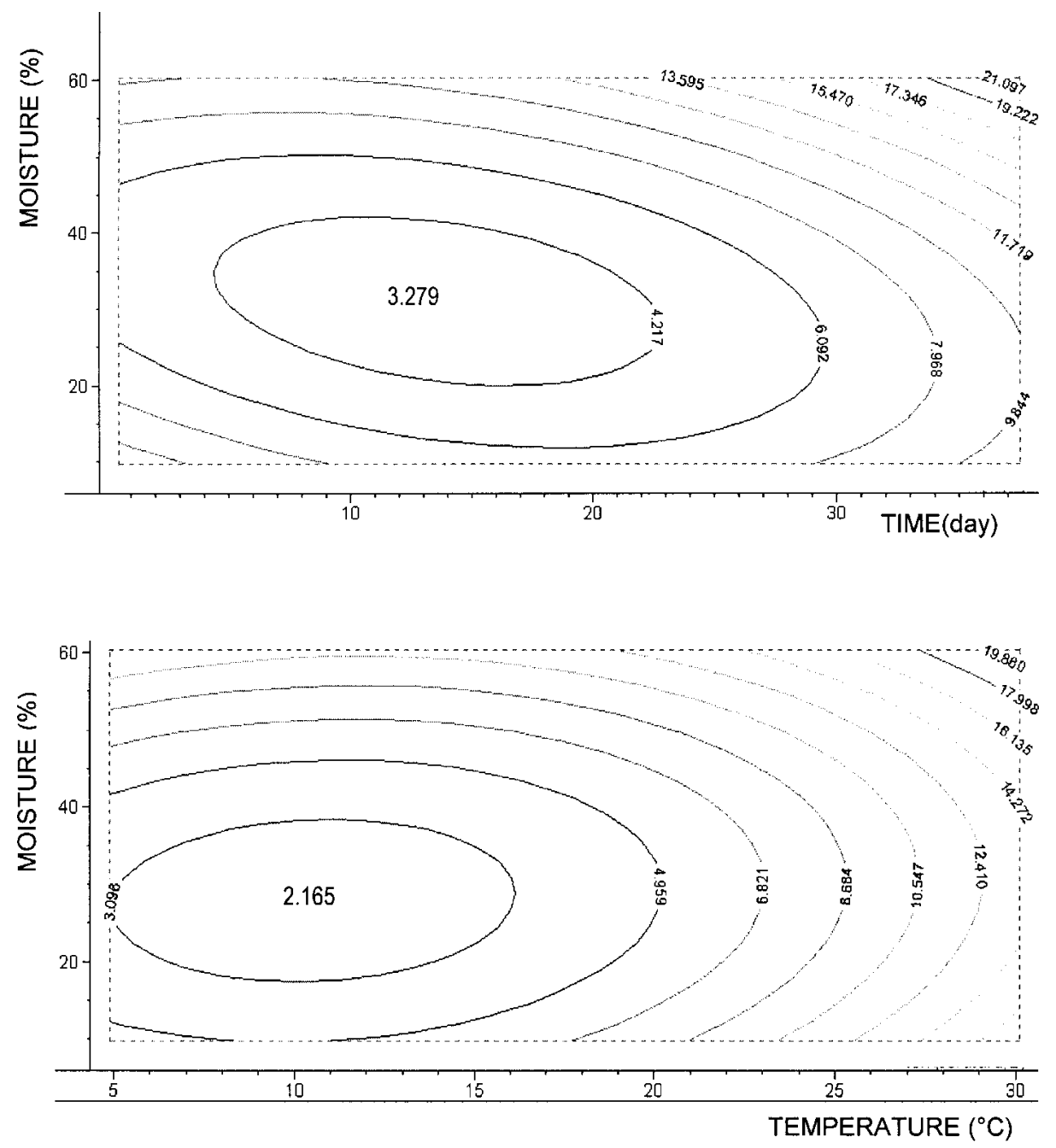

Figure 4. Isoresponse curves for $\Delta E$ as a function of moisture content and temperature at 19 days of storage time. 
considerable variation in $\Delta E$ (ie 2.17-4.96) occurred in dried tomato halves at $10-45 \%$ moisture content and $5-20^{\circ} \mathrm{C}$ storage temperature. The range that allows one to minimise colour variation at storage temperatures close to room temperature was $20-40 \%$ moisture content.

Combining all the above results with the results on microbial growth described previously (Table 3), optimisation by RSM allowed us to define the following optimal storage operating conditions under vacuum in the dark to minimise colour variation of and, indirectly, oxidative damage to dried tomato halves:

- $20-40 \%$ moisture content, corresponding to $a_{\mathrm{w}}=$ $0.69-0.86$ respectively, at $\leq 18^{\circ} \mathrm{C}$ storage temperature, with a minimum point of colour variation at approximately $30 \%$ moisture content and $10^{\circ} \mathrm{C}$.

\section{CONCLUSIONS}

Based on the results from this work, the following conclusions can be drawn.

Oxidative damage has to be minimised during storage of dried tomato to preserve sensory and nutritional characteristics of the product. Results show that temperature was the most important variable to minimise oxidative damage. In particular, at $\leq 18^{\circ} \mathrm{C}$ storage temperature, oxidative damage to dried tomato halves can be minimised during storage under vacuum in the dark.

The moisture content of dried tomato halves also played an important role. The moisture content has to be reduced during drying to obtain adequately low water activity values in order to decrease the velocity of oxidative damage kinetics and to inhibit growth of spoilage micro-organisms. Interestingly, adequate shelf-life seems to be obtained at relatively high moisture content (ie $30-40 \%$ ) and, consequently, at high water activity $(0.80-0.86)$.

This conclusion should be combined with another observation: a low moisture content (ie $\leq 12 \%$ ) of dried tomato halves seems to promote oxidative damage. This behaviour has been verified for lipid oxidation; when the moisture content falls below the monolayer moisture content of the product, an increase in oxidation can occur. ${ }^{15}$ The traditional production of dried tomato halves at low moisture content results in (i) significant oxidative heat damage due to both longer drying times and higher surface temperatures, ${ }^{1}$ (ii) additional significant oxidative damage during storage and (iii) thermal death of eumycetes on the surface of tomato halves.
For tomato-drying optimisation, complete dehydration of the product should be avoided to minimise oxidative damage to the product. Hence the setting up of new tomato products at intermediate moisture may be interesting for the tomato industry. Pilot tests are being carried out to verify this hypothesis in terms of technological aspects, sensory acceptability and nutritional value of these new products.

\section{ACKNOWLEDGEMENTS}

We are grateful to R Nani of IVTPA (Milan, Italy) for his help in drying and storage tests and to C Peri of diSTAM for planning the work.

\section{REFERENCES}

1 Zanoni B, Peri C, Nani R and Lavelli V, Oxidative heat damage of tomato halves as affected by drying. Food Res Int 31:395-401 (1999).

2 Cole ER and Kapur NS, The stability of lycopene. I. Degradation by oxygen. I Sci Food Agric 8:360-365 (1957).

3 Cole ER and Kapur NS, The stability of lycopene. II. Oxidation during heating of tomato pulps. F Sci Food Agric 8:366-368 (1957).

4 Khachik F, Goli MB, Beecher GR, Holden J, Lusby WR, Tenorio MD and Barrera MR, Effect of food preparation on qualitative and quantitative distribution of major carotenoids of tomatoes and several green vegetables. $\mathcal{F}$ Agric Food Chem 40:390-398 (1992).

5 Sharma SK and Le Maguer M, Kinetics of lycopene degradation in tomato pulp solids under different processing and storage conditions. Food Res Int 29:309-315 (1996).

6 Nicoli MC, Anese M, Parpinel MT, Franceschi S and Lerici CR, Loss and/or formation of antioxidants during food processing and storage. Cancer Lett 114:71-74 (1997).

7 Anese M, Manzocco L, Nicoli MC and Lerici CR, Antioxidant properties of tomato juice as affected by heating. $\mathcal{F}$ Sci Food Agric 79:750-754 (1999).

8 Baloch WA, Khan $S$ and Baloch AK, Influence of chemical additives on the stability of dried tomato powder. Int $\mathcal{F}$ Food Sci Technol 32:117-120 (1997).

9 Box GEP, Hunter WG and Hunter JS, Statistics for Experimenters. Wiley, New York (1978).

10 Alcaraz EC, Martin MA and Marin JP, Metodo manometrico para medida de humedades de equilibrio. Grasas y Aceites 28:403-407 (1977).

11 Francis FJ and Clydesdale FH, Food Colorimetry: Theory and Applications. AVI Publishing, Westport, CT (1975).

12 D'Souza MC, Singha S and Ingle M, Lycopene concentration of tomato fruit can be estimated from chromaticity values. HortSci 27:465-466 (1992).

13 Barreiro JA, Milano $M$ and Sandoval AJ, Kinetics of colour change of double concentrated tomato paste during thermal treatment. F Food Engng 33:359-371 (1997).

14 Stinson CG and Tiwari NP, Evaluation of quick bacterial count methods for assessment of food plant sanitation. F Food Protect 41:269-271 (1978).

15 Labuza TP, Kinetics of lipid oxidation in foods. CRC Crit Rev Food Technol 2:355-405 (1971). 